\title{
Sebuah Wawasan Tentang Bisnis Keluarga
}

\author{
Ajeng Putri Hanifah" ${ }^{* 1}$, Muhamad Rizal ${ }^{2}$, Ria Arifianti ${ }^{3}$ \\ 1,2,3 Universitas Padjadjaran \\ Bandung, Indonesia \\ *ajeng20015@mail.unpad.ac.id
}

\begin{abstract}
This article presents how the factors affecting family owned and managed businesses are examined and related to how the business literature develops. In addition, it discusses important patterns in the current literature and new directions regarding family business for future study. This study identifies the main research topics and methodical approaches in a systematic literature review to understand the family business. Insights about behind the historic changes and current directions and trends of family business literature are also identified. The findings of this study argue that the main cause of challenges in running a family business is sourced from managing the relationship between family interests and business interests. The key success factors are strong leadership and building a culture that accepts continuous change. Due to the specificity of family business dynamics and conflict in decision making, which can hardly be found by quantitative studies alone, it is advisable to use qualitative studies. The culture around decision making in family businesses has great value which is demonstrated in this study.
\end{abstract}

Keywords : Family Business; Governance; Planning for Success.

\begin{abstract}
Abstrak- Artikel ini meyajikan tentang bagaimana faktor-faktor yang mempengaruhi bisnis yang dimiliki dan dikelola oleh keluarga diuji dan terkait bagaimana literatur bisnis berkembang. Selan itu, membahas tentang pola-pola penting dalam literatur saat ini dan arah baru terkait bisnis keluarga untuk studi di masa depan. Penelitian ini mengidentifikasi topik penelitian utama dan pendekatan metodis secara tinjauan literature yang sistematis untuk memahami bisnis keluarga. Wawasan tentang di balik perubahan bersejarah dan arah serta tren literatur bisnis keluarga saat ini yang juga diidentifikasi. Temuan penelitian ini berpendapat bahwa yang menjadi penyebab utama adanya tantangan dalam menjalankan bisnis keluarga yaitu bersumber dari pengelolaan keterkaitan antara kepentingan keluarga dan kepentingan bisnis. Faktor kunci keberhasilannya yaitu kepemimpinan yang kuat dan membangun budaya yang menerima perubahan berkelanjutan. Karena kekhususan dari dinamika bisnis keluarga dan konflik dalam mengambil keputusan, yang hampir tidak dapat ditemukan oleh studi kuantitatif saja, disarankan untuk menggunakan studi kualitatif. Budaya seputar pengambilan keputusan dalam bisnis keluarga memiliki nilai besar yang ditunjukkan dalam studi ini.
\end{abstract}

Kata Kunci - Bisnis Keluarga; Merencanakan Kesuksesan; Tata Kelola.

\section{PENDAHULUAN}

Selama dua dekade terakhir, dalam penelitian bisnis keluarga telah tumbuh dan menjadi semakin ketat [1]-[3], ini merupakan sebuah bidang studi yang baru muncul [4]-[6]. Keragaman bisnis keluarga dan kinerjanya menjadikan mereka subjek yang layak untuk dieksplorasi. Sebagai contoh, banyak penelitian bisnis keluarga sebelumnya telah membahas topik umum termasuk: suksesi [7]-[9], konflik [10]-[12], dimensi kinerja [13]-[15] dan tata kelola [16]-[18]. Tetapi, pertimbangan terbatas telah diberikan untuk dampak dinamika keluarga"proses kewirausahaan mendasar" [19], [20], dalam mengatasi kompleksitas pengambilan keputusan pada bisnis keluarga lebih banyak diupayakan dan untuk memahami bagaimana mereka berbeda ataupun serupa dari jenis organisasi lain. Selain itu, masa depan bidang ini bergantung pada pemanfaatan masa lalu penelitian melalui identifikasi arah baru penelitian dan pendekatan metodis yang melengkapi, meningkatkan, dan memajukan penelitian sebelumnya. Tujuan dari tinjauan pustaka adalah untuk mengutip studi sebelumnya yang mencerminkan adanya perbedaan signifikan antara bisnis keluarga dan non-keluarga dan tantangan yang dihadapi dalam pengambilan keputusan. Selain itu, gambaran umum tersebut juga mencerminkan perbedaan wawasan dalam literatur kewirausahaan. Tantangan yang diamati terbagi dalam berbagai kategori. Ini adalah keuangan, manajerial, organisasi, struktural, strategis dan tata kelola. Tantangan juga berbeda antara bisnis keluarga dan bisnis non-keluarga.

Tinjauan pustaka ini akan sangat menarik bagi para pemegang saham bisnis keluarga dan anggota keluarga mereka, eksekutif bisnis non-keluarga dan anggota tim manajemen, penasihat keluarga pemilik bisnis, pejabat pemerintah dan komunitas akademis yang ingin belajar tentang masalah dan alat. syarat untuk berhasil memimpin bisnis milik keluarga ke masa depan.

\section{KAJIAN PUSTAKA}

Kajian literatur dituliskan dalam paragraf mengalir. Kajian literatur memaparkan tentang telaah dari berbagai referensi yang bersumber dari buku ilmiah umum, buku-buku teoritis, skripsi, tesis, disertasi dan jurnal ilmiah dan erat hubungannya dengan penelitian, penelitian sebelumnya berkaitan dengan judul penelitian, hipotesis penelitian. Selain itu 
kajian literatur berisi landasan teori yang ditampilkan dalam kalimat-kalimat lengkap, ringkas, serta benarbenar relevan dengan pendahuluan, tujuan penelitian. Sebagai contoh: Horngren dan Harrison (2017:4) menyatakan bahwa akuntansi merupakan sistem informasi yang mengukur aktivitas bisnis, memproses informasi menjadi laporan keuangan, dan mengkomunikan hasilnya kepada para pembuat pengambil keputusan.

Dalam rupa yang paling sederhana, bisnis keluarga mengacu pada bisnis yang dimiliki dan atau dikelola oleh sebuah keluarga [5], [21]-[23]. [21] mendefinisikan bahwa bisnis keluarga adalah bisnis yang kepemilikan dan keputusannya dibuat oleh anggota dari "kelompok kekerabatan". Lalu [23] mendefinisikan bahwa keterlibatan keluarga dalam bisnis sebagai "a substantial family presence in ownership, governance, management, succession, and/or employment" (hal.77). Namun, definisi umum menyatakan bahwa yang luas dari perusahaan keluarga adalah di mana sebuah keluarga memiliki cukup ekuitas untuk dapat menggunakan wewenang atas strategi dan terlibat langsung dalam posisi manajemen puncak. Definisi ini disampaikan oleh [24] seperti banyak definisi lainnya tidak jelas karena tidak berbicara dengan tingkat kendali yang diperlukan juga tidak berbicara dengan jumlah posisi manajemen puncak yang diperlukan, tetapi mencerminkan beberapa teori kewirausahaan sosiologis yang berbicara dengan faktor individu dan sosial / situasional. Oleh sebab itu, ikarenakan keragaman intrinsic, sulit untuk menyampaikan definisi tentang bisnis keluarga yang jelas [25].

Warisan dan nilai-nilai tradisi keluarga dalam bisnis ini sangatlah penting dan generasi muda cenderung akan menjadikannya referensi pada bagaimana cara keluarga mereka dalam menjalankan bisnis [26]-[28]. Hal ini penting karena warisan dan tradisi keluarga tetap terjaga dan menjadi kebiasaan yang menjangkar pengambilan keputusan. Ketaatan tradisi mengingatkan eksekutif keluarga muda saat ini dari mana bisnis itu berasal dan menciptakan struktur untuk pengambilan keputusan di masa depan. Ini mengakui nilai-nilai generasi sebelumnya, menginspirasi generasi berikutnya dan bertindak sebagai sumber kebanggaan bagi keluarga dan karyawan bisnis. Namun, kepemilikan keluarga dalam operasi bisnis keluarga ditantang untuk mempertahankan kekayaan dan status keluarga dengan melibatkan teknik non-tradisional yang lebih sesuai dengan usaha bisnis non-keluarga [24]. [29] (p. 657) mengklaim bahwa "in the large corporate sector, family capitalism was increasingly succeeded by managerial capitalism [...] [and] the entrepreneurial families were displaced." Sementara akademisi lain seperti [30] mengakui bahwa keberjalanan bisnis keluarga akan lebih efektif jika mereka berperilaku lebih seperti bisnis non-keluarga. Para profesional melakukan diskusi dan kompensasi dan [22] mengatakan bahwa di perusahaan keluarga, jenis konsep bisnis non-keluarga dapat disesuaikan. [31] mendapatkan sebuah temuan bahwa perusahaan keluarga terkadang mendapatkan manfaat dari penggunaan gagasan bisnis non-keluarga seperti pencarian dan seleksi, pembayaran berbasis kinerja dan praktik pemberdayaan karyawan. [30] menyarankan agar bisnis keluarga yang mengadopsi praktik non-keluarga dalam sistem kerja kinerja, mengungguli perusahaan non-keluarga, sedangkan mereka yang tidak melakukannya di bawah perusahaan non-keluarga yang dilakukan. Tantangan-tantangan ini telah muncul terutama karena meningkatnya peluang pasar dan persaingan yang sengit, dan dengan demikian praktik kewirausahaan baru mungkin penting bagi bisnis keluarga untuk berhasil di pasar yang terus berubah. [32] mengidentifikasi bahwa terdapat peran keluarga dalam menumbuhkan perilaku kewirausahaan di perusahaan keluarga. Setiap bisnis keluarga didirikan berdasarkan visi kewirausahaan, dan sepanjang siklus hidupnya semangat kewirausahaan yang jelas akan memungkinkan setiap generasi peluang baru untuk pertumbuhan [24]. Model organisasi terbaru menunjukkan bahwa semakin banyak bisnis yang membangun pemisahan antara kepemilikan dan operasi [33]-[35]. Peran pemilik bisnis keluarga dan pengelola bisnis harus dipandang terpisah dan berbeda meskipun sama-sama signifikan terhadap kesuksesan bisnis keluarga. Tantangan utama di sini adalah bahwa sementara pemilik bisnis keluarga sebagai manajer mungkin mengenakan dua topi, sulit untuk melakukan lebih dari satu peran pada satu waktu dalam pengambilan keputusan. Bagian berikutnya memeriksa bisnis milik keluarga dan dikelola vs usaha kewirausahaan tradisional (bisnis non-keluarga) [24].

\section{METODE PENELITIAN}

Model yang digunakan dalam penelitian ini sebagai berikut: Penelitian ini mengidentifikasi topik penelitian utama dan pendekatan metodis menggunakan SLR atau systematic literature review untuk memahami bisnis keluarga. Wawasan tentang di balik perubahan bersejarah dan arah serta tren literatur bisnis keluarga saat ini yang juga diidentifikasi. 


\section{HASIL DAN PEMBAHASAN}

\section{Bisnis Keluarga VS Bisnis non-Keluarga}

Bisnis keluarga biasanya dibedakan berdasarkan dimensi strategis dan organisasi mereka, serta keterlibatan keluarga dalam visi, kepemilikan, manajemen atau tata kelola perusahaan [36]-[39]. Hal ini mengarah pada perbedaan signifikan bisnis keluarga karena berkaitan dengan hubungan timbal balik yang kuat antara keluarga dan perusahaan. [40] menyebutkan perbedaan bisnis keluarga dari bisnis non-keluarga yaitu melalui tujuan, hubungan, aturan, evaluasi dan suksesi. Literatur bisnis keluarga menyoroti tiga jenis bisnis keluarga: bisnis yang dikelola pemilik / pendiri, kemitraan saudara kandung dan keluarga besar / konsorsium sepupu [41], [42]. Ini membawa legitimasi teori agensi, yang memberikan kerangka kerja terbaik untuk memahami perbedaan rumit antara bisnis milik keluarga dan bisnis bukan milik keluarga atau bisnis yang dikelola agen. Menurut [43],"di mana pemisahan kepemilikan dan kontrol ada, mekanisme kontrol agensi diberlakukan untuk menyelaraskan tujuan manajer (agen) dengan tujuan pemilik (prinsipal)"(hlm. 46-47). Namun, dari perspektif bisnis keluarga, tantangan yang biasanya muncul dengan bisnis non-keluarga mengenai keselarasan dengan manajer dan pemilik harus minimal mengingat bahwa manajer dan pemilik adalah satu dan sama [5], [44]-[46](Ramadani et al, 2017; Samara \& Arenas, 207; Diaz et al, 2019; Dacko, 2019). Dalam kasus seperti itu, di mana pemilik dan manajer adalah sama, kompleksitas penyelarasan yang lebih sedikit dibayangkan; akan tetapi, ini tidak selalu meningkatkan efektivitas pengambilan keputusan tetapi mempercepat efisiensi. Teori keagenan juga mengacu pada berbagai cara di mana agen, yang terkait dengan pengaturan kontrak dengan bisnis, memengaruhi perilakunya. [47] menyampaikan bahwa teori keagenan didasarkan pada keyakinan bahwa agen ekonomi individu memilih tindakan yang memaksimalkan utilitas pribadinya. Pengaturan kontrak ini mencakup struktur organisasi dan permodalan, pengambilan risiko dan kebijakan remunerasi.

Dari perspektif kewirausahaan, ini berbicara tentang pengaturan yang dibuat dengan karyawan dan kontrak eksternal lainnya. Dalam kasus bisnis yang bukan milik keluarga, manajer-agen, berbeda dengan pemilik dalam konteks ini, adalah manajer yang menjalankan bisnis tanpa memiliki kepemilikan saham. Sedangkan pemilik-manajer, sebaliknya, cenderung menciptakan nilai bisnis karena motivasi mereka berbeda. Ada hubungan langsung dengan kekayaan mereka yang dihasilkan dari pertumbuhan bisnis yang sukses. Literatur menunjukkan bahwa bisnis milik keluarga memiliki keanehan yang berbeda dan karakteristik unik yang terkait dengan suksesi, tata kelola, pengambilan keputusan dan kinerja, yang semuanya membedakan mereka dari bisnis lain [48]-[50]. Seringkali terdapat tumpang tindih antara kepemilikan, dewan direksi dan manajemen eksekutif yang melibatkan orang yang sama dari keluarga di ketiga domain [51]. Hal ini tidak umum dalam jenis bisnis lain, di mana pemisahan tugas adalah norma. Bisnis keluarga juga dicirikan oleh pandangan dominan tentang kepemilikan dan tata kelola [52]-[54], di mana tingkat keterlibatan bervariasi. Oleh karena itu, bagianbagian berikut mengeksplorasi masalah dalam mengelola bisnis keluarga, penyebab tantangan yang dihadapi dan efektivitas berbagai solusi.

\section{Permasalahan dalam Mengelola Bisnis Keluarga}

Menyeimbangkan aktivitas keluarga dan bisnis dalam bisnis keluarga merupakan tantangan bagi bisnis keluarga kontemporer [9], [55], [56]. Manajer pemilik menghadapi tantangan untuk menyeimbangkan tanggung jawab baik dalam keluarga maupun bisnis keluarga. Sebagian besar pemilik bisnis keluarga setuju semakin sulit untuk mencapai keseimbangan ini belakangan ini. Meskipun situasi keluarga berbeda, kekhawatiran umum tentang keseimbangan keluarga dan manajemen bisnis keluarga melibatkan hubungan, waktu dan energi[57].

Dari perspektif manajemen, konflik antara keluarga, anggota keluarga lain dan tanggung jawab kerja non-anggota keluarga seringkali menimbulkan ketegangan dalam bisnis [58]-[60]. Ketika konflik terjadi; baik keluarga maupun bisnis keluarga menderita. Penelitian telah mengidentifikasi peran struktur tata kelola sebagai prinsip utama untuk menjelaskan konflik ini [45], [61], [62](misalnya Samara \& Arenas, 2017; Shahzad et al, 2017; Heikkilä \& Bowman, 2018). Jadi, menyeimbangkan masalah bisnis dan keluarga; mengakibatkan kebutuhan akan instrumen tata kelola yang spesifik. Pembentukan struktur dewan dicatat dalam [63] yang menyatakan bahwa sifat, peran dan komposisi dewan berbeda dari satu organisasi ke organisasi lainnya tergantung pada ukuran, kompleksitas dan tahapan siklus hidup organisasi. [64] mengemukakan bahwa tujuan utama dewan adalah untuk memberikan kepemimpinan kepada organisasi dengan secara kolektif mengarahkan urusan perusahaan dan menetapkan kecepatan untuk operasinya saat ini dan pengembangan di masa depan. Banyak yang telah dikatakan tentang tata kelola 
perusahaan dan bisnis tetapi eksplorasi lebih lanjut dan penekanan dan detail yang lebih besar diperlukan dalam bagian literatur ini terkait dengan tata kelola perusahaan dalam struktur bisnis keluarga, terutama dengan kekhasannya terhadap kerahasiaan keluarga. Peran manajemen khusus dan pendidikan kewirausahaan diangkat sebagai cara yang mungkin ke depan untuk urusan perusahaan yang mengarahkan secara damai.

\section{Efektivitas dari Berbagai Solusi}

Jarang sekali bisnis milik keluarga menemukan solusi yang sederhana, cepat, dan tahan lama dengan tantangan / masalah yang mereka hadapi. Sebagian besar masalah kompleks dan harus diperiksa dari sejumlah sudut pandang sebelum solusi dapat dihasilkan atau bahkan diimplementasikan [65]-[67]. Namun, literatur telah menunjukkan bahwa dengan mengikuti pendekatan sistematis untuk pemecahan masalah, bisnis milik keluarga dapat membangun pemahaman yang komprehensif tentang masalah bisnis tertentu dan menemukan solusi yang bisa diterapkan[68]-[70]. Ada tiga langkah utama dalam menyelesaikan masalah bisnis: mengidentifikasi masalah, mengevaluasi opsi dan memilih solusi terbaik. Dari perspektif bisnis keluarga, kunci efektivitas berbagai solusi adalah membangun budaya yang menerima perubahan terus menerus. Hari ini fokus bisnis milik keluarga harus diarahkan untuk memimpin bisnis melalui perubahan berkelanjutan untuk meningkatkan kesadaran seputar pentingnya kepemimpinan, melibatkan inovasi, serta menantang produk dan praktik saat ini. Melalui kepemimpinan yang solid dan perencanaan suksesi kreatif di mana bisnis milik keluarga memastikan kompensasi yang adil untuk karyawan keluarga dan non-keluarga; lingkungan seperti itu akan mendorong wawasan strategis yang segar dari semua karyawan. Ini kemudian akan meminjamkan untuk membangun saluran untuk komunikasi yang konstruktif dan dalam jangka panjang menarik dan mempertahankan anggota non-keluarga yang sangat baik ke tim [24].

\section{KESIMPULAN DAN SARAN}

Mengelola tanggung jawab keluarga dan bisnis milik keluarga adalah salah satu tugas paling menantang bagi pemilik bisnis keluarga. Mengidentifikasi prioritas, strategi, sumber daya dan kekuatan dapat membantu menetapkan keseimbangan yang diperlukan untuk mengurangi konflik dan menjaga keluarga dan bisnis dalam keadaan yang baik. Penelitian menyoroti bahwa ada dua aliran paralel teori dan praktik kewirausahaan dan bisnis keluarga tetapi ada kekurangan teori terintegrasi yang akan membantu pembaca lebih memahami hubungan yang kompleks dan berubah antara keluarga dan bisnis keluarga. Sedangkan sebagian besar penelitian bisnis keluarga sebelumnya telah membahas topik umum yang meliputi: suksesi, konflik, dimensi kinerja dan tata kelola;

Temuan tinjauan pustaka ini menunjukkan bahwa penyebab utama dari tantangan dalam menjalankan bisnis keluarga berasal dari manajemen keterkaitan antara urusan keluarga dan urusan bisnis dan itulah yang menjadi alasan mengapa masalah kompleks dalam mengelola bisnis keluarga menjadi khas. hanya untuk bisnis keluarga. Penelitian juga menunjukkan bahwa keunikan dan kompleksitas masalah menimbulkan kebutuhan lebih lanjut untuk memeriksa masalah dari berbagai sudut pandang sebelum solusi dapat dihasilkan atau bahkan diimplementasikan.

Implikasi praktis dari tinjauan ini mengungkapkan beberapa aplikasi masuk akal yang layak untuk studi di masa depan. Memahami budaya seputar pengambilan keputusan dalam bisnis keluarga memiliki nilai yang tinggi. Karakteristik seperti agresivitas, keberanian, dan persaingan di antara pemilik bisnis keluarga dan anggota lain adalah bagian alami dari konstruksi untuk memahami tata kelola dan pengambilan keputusan dalam literatur bisnis keluarga.

Sementara tinjauan pustaka tentang wawasan bisnis keluarga berbagi fitur umum dalam memberikan pembaca latar belakang yang komprehensif untuk memahami pengetahuan terkini dan menyoroti pentingnya bidang penelitian baru; namun, mungkin ada beberapa perbedaan dalam beberapa poin penting tentang bagaimana hal ini dilakukan karena kesenjangan dalam literatur. Tinjauan pustaka saat ini menyampaikan signifikansi, pentingnya, dan sifat menarik dari penelitian yang sedang dilakukan? Fokus tinjauan adalah untuk menyoroti materi latar belakang yang relevan untuk mengidentifikasi kesenjangan, kelemahan, masalah atau kontroversi yang perlu ditangani. Akhirnya, penutupan dirancang untuk mengidentifikasi arah yang menjanjikan untuk penelitian di masa depan.

\section{REFERENSI}

[1] P. Jaskiewicz and W. G. Dyer, "Addressing the elephant in the room: Disentangling family heterogeneity to advance family business research," 2017.

[2] C. Salvato, F. Chirico, L. Melin, and D. Seidl, 
"Coupling family business research with organization studies: Interpretations, issues and insights," Organ. Stud., vol. 40(6), pp. 775791, 2019.

[3] A. De Massis and E. Rondi, "COVID-19 and the future of family business research," Manag. Stud., vol. 57(8), pp. 1727-1731, 2020.

[4] A. Motylska-Kuzma, "The financial decisions of family businesses," Fam. Bus. Manag., 2017.

[5] V. Diaz-Moriana, T. Hogan, E. Clinton, and M. Brophy, "Defining family business: A closer look at definitional heterogeneity," Palgrave Handb. Heterog. among Fam. firms, pp. 333374, 2019.

[6] M. Muhammad, C. E. Yet, M. Tahir, and A. M. Nasir, "Capital structure of family firms: the effect of debt and equity market timing," Fam. Bus. Manag., 2020.

[7] T. Nelson and C. Constantinidis, "Sex and gender in family business succession research: A review and forward agenda from a social construction perspective," Fam. Bus. Rev., vol. 30(3), pp. 219-241, 2017.

[8] L. Cisneros, M. Ibanescu, C. Keen, O. LobatoCalleros, and J. Niebla-Zatarain, "Bibliometric study of family business succession between 1939 and 2017: mapping and analyzing authors' networks," Scientometrics, vol. 117(2), pp. 919-951, 2018.

[9] J. A. Porfírio, J. A. Felício, and T. Carrilho, "Family business succession: Analysis of the drivers of success based on entrepreneurship theory," Bus. Res., vol. 115, pp. 250-257, 2020.

[10] A. Caputo, G. Marzi, M. M. Pellegrini, and R. Rialti, "Conflict management in family businesses," Int. J. Confl. Manag., 2018.

[11] L. V Effendi, "The Impact of Family Conflict toward Intention to Stay in the Family Business: The Moderating Effect of Socioemotional Wealth," Apl. Manaj., vol. 18(1), pp. 64-74, 2020.

[12] E. R. Kushins and E. Behounek, "Using sociological theory to problematize family business research," Fam. Bus. Strateg., vol. 11(1), p. 100337, 2020.

[13] A. C. Gonzalez, Y. Rodriguez, and A. Sossa, "Leadership and governance decisions in family business performance: An application of fuzzy sets logic," Small Bus. Strateg., vol. 27(1), pp. 51-66, 2017.

[14] R. Basco, A. Calabrò, and G. Campopiano,
"Transgenerational entrepreneurship around the world: Implications for family business research and practice," Fam. Bus. Strateg., vol. 10(4), p. 100249, 2019.

[15] I. M. García-Sánchez, J. Martín-Moreno, S. A. Khan, and N. Hussain, "Socio-emotional wealth and corporate responses to environmental hostility: Are family firms more stakeholder oriented?," Bus. Strateg. Environ., vol. 30(2), pp. 1003-1018, 2021.

[16] B. D. Piana, A. Vecchi, and A. Jimenez, "Embracing a new perspective on the governance of family business groups: a crosscultural perspective," Eur. J. Int. Manag., vol. 12(3), pp. 223-254, 2018.

[17] C. Dibrell and E. Memili, "A brief history and a look to the future of family business heterogeneity: An introduction," Palgrave Handb. Heterog. among Fam. firms, pp. 1-15, 2019.

[18] V. Bodolica, D. Dupuis, and M. Spraggon, "At the intersection of corporate governance and performance in family business settings: Extant knowledge and future research," Bus. Ethics A Eur. Rev., vol. 29(1), pp. 143-166, 2020.

[19] A. Discua, "Rethinking entrepreneurship and family business research in Honduras: a closer look in times of crisis," Innovare Rev. Cienc. $y$ Tecnol., vol. 9(1), pp. 28-38, 2020.

[20] H. . Aldrich and J. . Cliff, "The pervasive effects of family on entrepreneurship: toward a family embeddedness perspective," Bus. Ventur., vol. Vol. 18 No, pp. 573-596, 2003.

[21] A. Casrud, "Lessons learned in creating a family business program," Entrep. Theory Pract., vol. 19 No. 1, pp. 39-41, 1994.

[22] J. . Chua, J. . Chrisman, and E. . Bergiel, “An agency theoretic analysis of the professionalized family firm," Entrep. Theory Pract., vol. 33 No. 2, pp. 355-372, 2009.

[23] A. Intihar and J. . Pollack, "Exploring small family-owned firms' competitive ability: differentiation through trust, value -orientation, and market specialization," Fam. Bus. Manag., vol. 2 No. 1, pp. 76-86, 2012.

[24] S. Goel and R. J. Jones, "Entrepreneurial Exploration and Exploitation in Family Business: A Systematic Review and Future Directions," Fam. Bus. Rev., vol. 29, no. 1, pp. 94-120, 2016, doi: $10.1177 / 0894486515625541$

[25] A. Colli and M. . Rose, "The Oxford Handbook 
of Business History," in Oxford University Press, 2008.

[26] M. J. Parada and A. Dawson, "Building family business identity through transgenerational narratives," Organ. Chang. Manag., 2017.

[27] M. D. O. Dias and E. Davila Jr, "Overcoming succession conflicts in a limestone family business in Brazil," Bus. Manag. Rev., vol. 6(7), pp. 58-73, 2018.

[28] C. Vallone and B. Iannone, "Innovation trough Tradition in Family Business," Bus. Manag., vol. 15(1), 2020.

[29] A. Giddens and S. Griffiths, Sociology, 5th ed. Malden, MA: Polity Press, 2006.

[30] A. Stewart and M. Hitt, "Why can't a family business be more like a nonfamily business? Modes of professionalization in family firms," Fam. Bus. Rev., vol. 25 No. 1, pp. 58-86, 2012.

[31] C. Tsao, S. Chen, C. Lin, and W. Hyde, "Founding family ownership and firm performance: the role of high performance work systems," Small Bus. Enterp. Dev., vol. 11 No. 2, pp. 186-194, 2009.

[32] F. . Kellermanns and K. Eddleston, "Corporate venturing in family firms: Does the family matter?," Entrep. Theory Pract., vol. 30 No. 6, pp. 837-854, 2006.

[33] O. Laasch, "Beyond the purely commercial business model: Organizational value logics and the heterogeneity of sustainability business models," Long Range Plann., vol. 51(1), pp. 158-183, 2018.

[34] A. D. Cruz and R. Basco, "Family perspective on entrepreneurship," in The Palgrave Handbook of Multidisciplinary Perspectives on Entrepreneurship, 2018, pp. 147-175.

[35] G. Arcese, M. Valeri, S. Poponi, and G. C. Elmo, "Innovative drivers for family business models in tourism," Fam. Bus. Manag., 2020.

[36] G. Flamini, L. Gnan, and M. M. Pellegrini, "Forty years of research on human resource management in family firms: analyzing the past; preparing for the future," Fam. Bus. Manag., 2020.

[37] M. Azizi, M. S. Bidgoli, and A. S. Bidgoli, "Trust in family businesses: A more comprehensive empirical review," Cogent Bus. Manag., vol. 4(1), p. 1359445, 2017.

[38] M. Caccamo, D. Pittino, and F. Chirico, "Family firm density and likelihood of failure: An ecological perspective," in The Palgrave handbook of heterogeneity among family firms,
2019, pp. 821-846.

[39] S. Amato, R. Basco, S. G. Ansón, and N. Lattanzi, "Family-managed firms and employment growth during an economic downturn: does their location matter?," Balt. J. Manag., 2020.

[40] W. . Dyer, The Entrepreneurial Experience. San Francisco: Jossey-Bass, 1992.

[41] K. . Gersick, J. . Davis, M. . Hampton, and I. Lansberg, "Generation to Generation: The Life Cycles of The Family Business," in Harvard Business School Press, 1997, pp. 38-39.

[42] P. Westhead and C. Howorth, "Types of private family firms: an exploratory conceptual and empirical analysis," Entrep. Reg. Dev., vol. 19 No. 5, pp. 405-431, 2007.

[43] M. Duh, "Applying agency theory and the resource-based view in explaining performance differences between family and non-family businesses," NaseGospodarstvo, vol. 56 Nos 1/2, p. 45, 2010.

[44] Z. Dacko-Pikiewicz, "Building a family business brand in the context of the concept of stakeholder-oriented value," in Forum Scientiae Oeconomia, 2019, pp. 37-51.

[45] G. Samara and D. Arenas, "Practicing fairness in the family business workplace," Bus. Horiz., vol. 60(5), pp. 647-655, 2017.

[46] V. Ramadani, L. P. Dana, N. Sadiku-Dushi, V. Ratten, and D. H. Welsh, "Decision-making challenges of women entrepreneurship in family business succession process," enterprising Cult., vol. 25(04), pp. 411-439, 2017.

[47] D. . Denis, D. . Denis, and S. Atulya, "Agency theory and the influence of equity ownership structure on corporate diversification strategies," Strateg. Manag. J., vol. 20 No. 11, pp. 1071-1076, 1999.

[48] T. M. McDonald and M. I. Marshall, "Family business responses to household and business cash-flow problems," Fam. Econ. Issues, vol. 39(1), pp. 163-176, 2018.

[49] W. Li and M. I. Marshall, "Gender and business owner satisfaction: The case of farm and nonfarm family businesses in the Midwest," Fam. Bus. Manag., vol. 9(4), pp. 416-428, 2019.

[50] P. Harris and O. Ozdemir, "Turkish delight a public affairs study on family business: The influence of owners in the entrepreneurship orientation of family-owned businesses," Public Aff., vol. 20(1), p. e2082, 2020. 
[51] N. . Miller, M. . Fitzgerald, M. Winter, and J. Paul, "Exploring the overlap of family and business demands: household and family business managers' adjustment strategies," Fam. Bus. Rev., vol. 12 No. 3, pp. 253-268, 1999.

[52] F. Visintin, D. Pittino, and A. Minichilli, "Financial performance and non-family CEO turnover in private family firms under different conditions of ownership and governance," Corp. Gov. An Int. Rev., vol. 25(5), pp. 312337, 2017.

[53] C. W. Tsao, M. J. Wang, C. M. Lu, S. J. Chen, and Y. H. Wang, "Internationalization propensity in family-controlled public firms in emerging markets: The effects of family ownership, governance, and top management team heterogeneity," Small Bus. Strateg., vol. 28(1), pp. 28-37, 2018.

[54] R. S. Burt, S. Opper, and N. Zou, "Social network and family business: Uncovering hybrid family firms," Soc. Networks, vol. 65, pp. 141-156, 2021.

[55] S. Arsić, K. Banjević, A. Nastasić, D. Rošulj, and M. Arsić, "Family business owner as a central figure in customer relationship management," Sustainability, vol. 11(1), p. 77, 2019.

[56] L. Vilčeková, B. Mucha, T. Peráček, and L'. Strážovská, "Selected issues of family business in selected countries with emphasis on the Slovak Republic," Innov. Manag. Educ. Excell. through Vis., vol. 4, p. 6, 2020.

[57] J. Leaptrott and J. . McDonald, "The conflict between work and family roles: the effects on managers' reliance on information sources in dealing with significant workplace events," Behav. Stud. Bus., vol. 15 No. 2, pp. 1-12, 2010.

[58] J. L. Gallizo, C. Mar-Molinero, J. Moreno, and M. Salvador, "Family business and valueadded distribution: a socioemotional wealth approach," Acad. Rev. Latinoam. Adm., 2017.

[59] M. McAdam, E. Clinton, and C. Dibrell, "). Navigation of the paradoxical landscape of the family business," Int. Small Bus. J., vol. 36(3), pp. 359-360, 2018.

[60] E. Rondi, A. De Massis, and J. Kotlar, "Unlocking innovation potential: A typology of family business innovation postures and the critical role of the family system," Fam. Bus. Strateg., vol. 10(4), p. 100236, 2019.
[61] M. Heikkilä and H. Bowman, "Business Model Innovation in European SMEs-Descriptive analysis of quantitative survey and case survey data," in Bled eConference, 2018, p. 4.

[62] F. Shahzad, S. A. Rauf, A. Saeed, and S. Al Barghouthi, "EARNING MANAGEMENT STRATEGIES OF LEVERAGED FAMILY AND NON-FAMILY CONTROLLED FIRMS: AN EMPIRICAL EVIDENCE," Int. $J$. Bus. Soc., vol. 18, 2017.

[63] P. Gubitta and M. Gianecchini, "Governance and flexibility in family-owned SMEs," Fam. Bus. Rev., vol. 15 No. 4, 2002.

[64] A. Pierce and H. Moukanas, "Portfolio power: harnessing a group of brands to drive profitable growth," Strateg. Leadersh., vol. 30 No. 5, pp. 15-21, 2002.

[65] F. M. Cesaroni and A. Sentuti, "Family business succession and external advisors: the relevance of 'soft'issues," Small Enterp. Res., vol. 24(2), pp. 167-188, 2017.

[66] G. Samara, D. Jamali, and M. Lapeira, "Why and how should SHE make her way into the family business boardroom?," Bus. Horiz., vol. 62(1), pp. 105-115, 2019.

[67] T. Zellweger, Managing the family business: Theory and practice. Edward Elgar, 2017.

[68] A. W. Alkahtani, "Family-Owned Businesses in Saudi Arabia: Challenges and Solutions from a Legal Perspective,". Int. J. Contemp. Manag. Inf. Technol, vol. 1(2), pp. 16-22, 2021.

[69] J. Greblikaitè, R. Rakštys, and D. Caruso, "Social entrepreneurship in rural development of Lithuania," Manag. Theory Stud. Rural Bus. Infrastruct. Dev., vol. 39(2), pp. 157-165, 2017.

[70] E. S. Wang and C. L. Lin, "How work design characteristics affect service employees' workfamily conflicts," Serv. Ind. J., vol. 38(13-14), pp. 925-947, 2018. 